\title{
ACTITUDES HOMÓFOBAS DE LOS ESTUDIANTES DE LA UNIVERSIDAD NACIONAL JORGE BASADRE GROHMANN, TACNA 2015
}

HOMOPHOBIC ATTITUDES OF STUDENTS OF JORGE BASADRE GROHMANN NATIONAL UNIVERSITY, TACNA 2015

\author{
Carmen Luisa Linares Torres ${ }^{1}$, Gema Natividad Sologuren García ${ }^{2}$
}

\begin{abstract}
RESUMEN
La presente investigación tiene como objetivo, evaluar y analizar las posibles actitudes homófobas de los estudiantes de la Universidad Nacional Jorge Basadre Grohmann en la ciudad de Tacna en el año 2015. Es un estudio de tipo cualitativo, descriptivo. La unidad de observación fueron los estudiantes (identificados a sí mismos como heterosexuales), cuyas edades oscilaron entre los 17 y 21 años. Se formaron dos grupos focales. Los resultados fueron: Los estudiantes muestran homofobia cognitiva, afectiva y conductual, lo cual es perpetuado en los hogares y en las instituciones educativas, promovida por los sectores conservadores de la sociedad y por los medios de comunicación. A pesar de expresar que no rechazan a los homosexuales, sí los estigmatizan, aceptando tácitamente la homofobia conductual de sus pares, les parece aceptable darles derechos políticos y sociales, pero no apoyan la defensa de sus derechos sexuales: hay rechazo hacia la paternidad de parejas homosexuales, aunque estarían de acuerdo con la unión civil. En la familia, se acepta y promueve la discriminación sexual. En las instituciones educativas de nivel primario y secundario, se inicia la práctica de la discriminación y se refuerzan las actitudes estigmatizantes por orientación sexual. Es necesario capacitar a docentes y padres de familia para evitar la homofobia en los hogares y en la escuela.
\end{abstract}

Palabras clave: Actitudes, estudiantes, homofobia, homosexualidad.

\section{ABSTRACT}

The present investigation has as main objective to evaluate and to analyze the possible homophobic attitudes of the students of Jorge Basadre Grohmann National University, Tacna, in the year 2015. It is a qualitative, descriptive study. The observation unit was the students (identified themselves as heterosexual), whose ages ranged between 17 and 21 years. Two focus groups were formed. The results were: students show cognitive, affective and behavioral homophobia, which is perpetuated in homes and in educational institutions, promoted by the conservative sectors of society and by the media. Despite expressing that they do not reject homosexuals, they do stigmatize them, tacitly accepting the behavioral homophobia of their peers, it seems acceptable to give them political and social rights, but they do not support the defense of their sexual rights: there is rejection of paternity of homosexual couples, although they would agree with the civil union. In the family, sexual discrimination is accepted and promoted. In educational institutions at the primary and secondary levels, the beginning of the practice of discrimination and stigmatizing attitudes are reinforced by sexual orientation. It is necessary to train teachers and parents in order to avoid homophobia in homes and at school.

Keywords: Attitudes, students, homophobia, homosexuality.

${ }^{1}$ Doctora en Ciencias de la Educación, Facultad de Ciencias de la Salud, Escuela Profesional de Obstetricia, Universidad Nacional Jorge Basadre Grohmann, Tacna-Perú.E-mail: clinares40@hotmail.com

${ }^{2}$ Doctora en Ciencias de la Educación, Facultad de Ciencias de la Salud, Escuela Profesional de Obstetricia, Universidad Nacional Jorge Basadre Grohmann, Tacna-Perú. E-mail: gemasologuren5@hotmail.com

Presentado: 31/03/17 Aprobado: 20/07/17 


\section{INTRODUCCIÓN}

Es evidente que las actitudes homófobas en los jóvenes están presentes. Erradicar la violencia y la discriminación que se ejerce permitirá el desarrollo de la salud integral, tal como lo señala la Organización Mundial de la Salud (1996): la salud es un estado de completo bienestar físico, mental y social, no solo la ausencia de afecciones o enfermedades. Luchar contra la homofobia en el sistema educativo (nivel primario, secundario 0 superior) contribuirá a la justicia social y a la salud integral, porque esta afecta indudablemente en el modo en que vive la gente, aumenta la probabilidad de enfermar y el riesgo de morir (OIT, 2007).

Diferentes autores han definido la homofobia como una actitud negativa, hostil e irracional hacia los homosexuales que puede manifestarse en acoso, abuso verbal, ataques violentos y hasta homicidios (Friedman y Downey, 1994). Asimismo, la definen como una antipatía hacia homosexuales y lesbianas que incluye condenación, desprecio, miedo y proscripción de la conducta homosexual (Castañeda, 2000; Fone, 2003; Pharr, 1997).

Snively et al. (2004) sostienen que la homofobia se manifiesta en respuestas afectivas, actitudes negativas basadas en mitos/estereotipos acerca de las relaciones entre personas del mismo sexo.

La homofobia no solamente afecta a las personas homosexuales, sino también a aquellas que por su apariencia, actitud o comportamiento se presupone que tienen una orientación homosexual. Y en un sentido más amplio, también la sufren todas aquellas personas que no cumplen estrictamente los roles de género. El sexismo implica no solamente la subordinación de lo femenino a lo masculino, sino también la jerarquización de las sexualidades, fundamento de la homofobia (Borrillo, 2001). Esta jerarquización de la sexualidad es lo que se denomina heterocentrismo, colocando a la heterosexualidad en el nivel superior y al resto de orientaciones sexuales como incompletas, inmorales, patológicas, destructoras de la civilización. Esto unido a la existencia actual de diferentes formas de vivir la feminidad y la masculinidad o desconociendo los roles de género, haciendo que se difuminen las fronteras entre lo masculino y lo femenino. Por todo ello, podemos ver que la identidad masculina actual se construye sobre la homofobia, y que la mujer lesbiana se siente como una amenaza para la civilización.

Según la fundación Reflejos de Venezuela (2015), existen tres tipos de homofobias:
- Cognitiva, referida a las ideas y conceptos anácronicos que se tienen sobre los homosexuales.

- Afectiva, relacionada con sentimientos de rechazo que afloran en determinadas personas al tener que relacionarse con homosexuales.

- Conductual, referida a comportamientos hacia personas homosexuales. Pueden ir desde la burla, chistes hasta la agresión física.

Por otro lado, la encuesta nacional sobre discriminación en México (CONAPRED 2010), muestra que el $40 \%$ de la población mostró rechazo hacia las expresiones no heterosexuales, y estuvo más marcado en las ciudades y localidades pequeñas, en los adultos con menos escolaridad y menores recursos económicos.

Toro y Varas (2004) indagaron en el prejuicio y la distancia social hacia homosexuales y lesbianas en la Universidad de Puerto Rico. Aplicaron una escala de distancia y otra de prejuicio social a una muestra de 548 alumnos. Las puntuaciones más altas indicaron mayor rechazo y a la inversa; los hombres obtuvieron más puntos que las mujeres. No obstante, también apareció una diferencia entre quienes conocían a una persona gay o lesbiana de quienes no, porque los primeros tuvieron un puntaje menor. Lo mismo ocurrió con la religión, porque a mayor religiosidad mayor prejuicio y distancia.

Goffman (1993) sostiene que vivimos en una sociedad heterosexista, donde al homosexual se le clasifica de una forma negativa, se le ridiculiza, se le teme o se le agrede, lo que denominó estigma (marca que destaca un atributo considerado nocivo). Quien es estigmatizado llega a convertirse en un ser despreciado, peligroso, débil, diferente.

Cárdenas y Barrientos (2008) utilizaron un test de asociación implícita para medir la fuerza asociativa de dos atributos que aplicaron a estudiantes de la licenciatura en ingeniería de una universidad chilena. Encontraron que los jóvenes pueden considerarse igualitarios en su trato con homosexuales; sin embargo, de una manera oculta 0 inconsciente, en el grupo de mujeres aparecieron prejuicios y homofobia implícita cercanos a los de los hombres.

Lizana (2009) investigó las representaciones sociales de la heterosexualidad y la homosexualidad en estudiantes de pedagogía. Descubrió que los conservadores no aceptan la homosexualidad, mientras que los liberales la admiten; pero sólo si hay discreción, es decir, la no exhibición pública de su preferencia. La indiscreción es algo intolerable, porque consideran que el cariño entre personas del mismo sexo debe expresarse en espacios privados. 
Campo et al. (2008) llevaron a cabo un estudio sobre las actitudes de los estudiantes ante el homosexual; seleccionaron una muestra de 600 alumnos de pregrado de la Universidad Central de Venezuela, y aplicaron una escala de actitudes. Encontraron que las respuestas homogéneas y favorables hacia el homosexual fueron de los alumnos de letras, estudios internacionales, comunicación social, psicología y sociología, a diferencia de los de computación y bioanálisis, quienes mostraron mayor rechazo.

Pulido et al. (2013) investigaron los niveles de homofobia en dos universidades religiosas de la Ciudad de México; su hallazgo fue que a mayor religiosidad, mayor homofobia. Sin embargo, cuando los estudiantes tienen algún conocido o amigo homosexual, el puntaje disminuye de manera importante. Además, descubrieron que los hombres fueron más homofóbicos que las mujeres.

La presente investigación responde a la siguiente interrogante:

¿Existen actitudes homófobas en los estudiantes de la Universidad Nacional Jorge Basadre Grobmann de Tacna 2015?

\section{OBJETIVOS}

\section{Objetivo general}

Evaluar y analizar las posibles actitudes homófobas de los estudiantes de la Universidad Nacional Jorge Basadre Grohmann de Tacna, 2015.

\section{Objetivos específicos}

a) Describir y analizar la homofobia cognitiva de los estudiantes.

b) Analizar y evaluar la homofobia afectiva de los estudiantes.

c) Determinar y analizar la homofobia conductual de los estudiantes.

d) Precisar la normalización de la violencia homófoba de los estudiantes.

e) Indagar el temor al contagio (el estigma) de los estudiantes.

\section{MATERIALESY MÉTODOS}

Este trabajo corresponde a la investigación cualitativa, descriptiva, enmarcada en el área de las ciencias de la salud y psicología; unidad de observación: estudiantes (hombres y mujeres) de la Universidad Nacional Jorge Basadre Grohmann de Tacna en el año 2015. Se formaron dos grupos focales, (cada grupo de 12 estudiantes), cuyas edades oscilaron entre los 17 y 21 años, seleccionados aleatoriamente. El tipo de muestreo fue intencional, se utilizó la estrategia "bola de nieve".

Cada grupo focal se desarrolló en fechas distintas dentro del espacio universitario, con una duración de 120 minutos aproximadamente. Se obtuvo autorización de los participantes para grabar la sesión; previamente se les comunicó los objetivos del estudio y que la información tenía fines exclusivos de investigación, se garantizó la confidencialidad. Algunos de ellos utilizaron nombres ficticios. Se utilizó como instrumento una guía conversatorio. Luego, las autoras de la investigación aplicaron y transcribieron la entrevista para su posterior análisis, clasificación según los objetivos, reducción de datos y codificación. Finalmente, se analizó el discurso.

\section{RESULTADOS}

\section{Concepto de homosexualidad}

Los estudiantes tienen claro que la homosexualidad se refiere a la atracción emocional, erótica y afectiva entre personas del mismo sexo. Ellos identifican en sus definiciones, vida afectiva, intimidad, atracción sexual y relación sexual.

"Bueno, defino la homosexualidad como la relación entre dos hombres, tanto afectiva como intima... su vida sexual y simplemente ese vínculo que nosotros normalmente conocemos, entre un hombre y una mujer... pero entre hombres". Silvia

\section{"La homosexual idad es la atracción de dos personas del mismo sexo y para mi es algo que abora, en la realidadya es normal". Luis Enrique}

Algunos estudiantes incluyen, en sus definiciones, el concepto de derechos, de aceptación social, forma de relacionarse sexualmente entre seres humanos. Se maneja como concepto de "pareja normal" la heterosexual, en consecuencia, consciente 0 inconscientemente, definen a la pareja homosexual como "anormal". Lo que se podría entender como una aceptación tácita del concepto tradicional de pareja, aunque señalen que la sociedad actual ha aceptado la relación homosexual como una forma más de vivencia de la sexualidad.

"Yo pienso que la bomosexualidad como dice mi compañero, es la relación entre dos personas del mismo sexo, las cuales comparten los mismos derechos y las mismas características que una pareja normal, por ejemplo: hombrey mujer... para mí es eso". Alex 
No todos los jóvenes aceptan como "normal" la existencia de parejas homosexuales, aunque piensen que la sociedad ha aprendido o está aprendiendo a aceptar esta forma de amar, de relacionarse.

"Yo tengo dos cosas bien claras, una que es el sexo: hombre mujer y otra es la sexualidad: que es la facultad, de cómo tú expresas tu sexo, puede ser un hombre que le gustan la mujeres; como puede ser un hombre que le guste también alguien de su mismo sexo y para mí, también es normal, antes no lo tomaba como abora... bueno, para mi es normal, pero para la sociedadno". Paolo

Para algunos estudiantes, la causa de la homosexualidad tendría origen en la búsqueda de afecto. Los jóvenes no tienen una información importante al respecto, porque al parecer no han tenido interés personal sobre el tema. Solo mencionan lo que han visto u oído a través de los medios de comunicación, los comentarios de otras personas, no necesariamente autorizadas en el tema. Más aún, no es un tema que se discute en la familia.

"¿Por qué existe la homosexualidad?... no sé, yo creo que ellos encuentran el afecto en personas de su mismo sexo”. Silvia

Los significados sobre la homosexualidad que predominan entre los estudiantes evidencian un conjunto de creencias erróneas sobre su origen. Por ejemplo, está la idea que una persona se convierte en homosexual por decepción amorosa en una relación heterosexual. Es decir, que sus preferencias sexuales no son parte de su naturaleza, sino que las vivencias sexuales frustrantes las llevan a "optar" por el homosexualismo. En otras palabras, una persona nace con una determinada orientación sexual y son las circunstancias e influencias del medio social en el que viven las que van a determinar su condición de homosexual. Una de estas circunstancias puede ser el haber sido víctima de abuso sexual.

“'Planteármelano?, pero sí he hablado sobre este tema o algo así, por ejemplo... bastante he visto en la televisión... algunos pues, optan por el caso de los gay, por ejemplo: el hecho de que ven, o varias mujeres les han fallado en muchas de sus relaciones y pues... han optadoporpersonas delmismo género". Richard

"En mi caso yo diría que se basa más que todo, en no haber nacido así (homosexual) sino, por las experiencias que han vivido, entonces han optado por eso, tanto hombres como mujeres, por las experiencias que han vivido ino? ... decepciones amorosas, problemas... tal vez alguna influencia en su propia familia ino? o también amigos cercanos a su círculo". Renato

Es importante observar cómo algunos jóvenes tienden a buscar una explicación sobre las causas del homosexualismo a partir de la genitalidad. A partir de dicha idea, construyen el concepto de "opción" refiriéndose a que un hombre 0 una mujer eligen o toman una decisión sobre si se relacionarán eróticamente con su mismo sexo o con el sexo opuesto.

"Para mi también, no me parece que se nace, porque nacer como dice mi compañero... cada persona nace con un sexo definido, es hombre o mujer, aunque bay veces que nacen con los dos tipos de sexo o también dos aparatos reproductores, pero más que todo nacen con un sexo definido, sexo y sexualidad es la actitud que tú optas, yo puedo ser hombre, me pueden gustar las mujeres o también me pueden gustar los hombres, puedo ser mujer y también me pueden gustar los hombres, pero también las mujeres, es la sexualidad que tú tomas o sea... un compañero también puede sufrir un trauma, también puede depender de tu entorno". Edwing.

\section{Estereotipos}

Los jóvenes consideran que las relaciones de género pueden determinar 0 al menos influenciar en gran medida, la orientación sexual de una persona. Por ejemplo estudiar con muchas mujeres puede determinar que un hombre sea un afeminado u homosexual.

"Yo tengo una anécdota de un compañero que estudiaba en un colegio de puras mujeres y después él se hizo homosexual". Paolo

"También creo, que obviamente no nacen, sino se bacen y yo pienso particularmente que eso es, porque es el entorno lo que hace a la persona homosexual". Jesús

Para algunos estudiantes, las experiencias "negativas" durante el inicio de la vivencia de su sexualidad con el sexo opuesto, influyen en la identidad sexual de las personas; pero consideran además que existe un factor biológico que determina su predisposición hacia la homosexualidad. Tomando en cuenta que esta se genera por un problema hormonal, genético o por ingerir alimentos con hormonas femeninas en el caso de los varones.

"Los homosexuales no nacen, cada persona nace con un sexo definido que en el transcurso de su vida pueda tener varias cosas que lo influyen para serlo, o también 
hay factores como: alimentos que contienen hormonas y hace que una persona sea y tenga más características de mujer, eso también hace que sean homosexuales, en la selva como bay frutos con hormonas, con estrógenos, por eso se hacen los homosexuales, ino nacen!... por ejemplo: la cocona tiene bastantes hormonas femeninas, el aguaje tambiény eso". Luis Enrique

"Yo la verdad sobre el tema (el ingerir ciertos alimentos te hace homosexual) no estoy muy bien informado, no sé, siempre me he preguntado yo, pero nunca be tenido la curiosidad de averiguar, no es que ellos nacen asío luego con el tiempo empiezan a tener otros gustos, eso no sé". Alex

Los estudiantes reconocen que la homosexualidad ha existido siempre. Lo que sucede en los últimos tiempos permite evidenciar que las personas están haciendo pública su condición de homosexual. Una de las razones sería la pérdida del temor a enfrentar la crítica de la sociedad, considerando que ésta ha aprendido a ser más tolerante con la diversidad sexual. Asimismo, manifiestan que, en la actualidad, "ya es normal" identificarse como homosexual.

"Como dice mi compañero, no es que haya más homosexuales, son los mismos, solo que antes no lo decían abiertamente... como decimos nuestros compañerosy yo: la homosexualidad abora ya es normal, antes no lo era, antes había chicos que tenían miedo de sentir algo por un hombre o una mujer cuando era atraída por otra mujer, no era normal, ahora se dice que es normal la homosexualidad, hay varios jóvenes que ya ven normal la homosexualidad... yo también me puedo enamorar, soy heterosexual me gustan las mujeres, pero como veo que la bomosexualidad en la sociedad es normal, también me puedo enamorar de un hombre, también puede ser una posibilidad". Paolo

"Como todos los jóvenes lo ven normal... a mí me podría gustar mi compañero.... creo que... abora como ya es normal, puedo decirlo... antes solo lo pensaba". Cesar

Si bien es cierto, los jóvenes manifiestan que consideran como "normal" las relaciones homosexuales que expresan pública y abiertamente sus afectos, se puede afirmar que esto no es real, pues tienen sentimientos de rechazo frente a una persona homosexual, ya que no se sienten cómodos relacionándose con ellos. En consecuencia, podría ser considerado como homofobia no visibilizada.

"Si un homosexual se acerca a mí y me dice que le gusto, para mí sería muy raro y yo me alejaría de él mirándolo a la cara, pero no baciéndolo sentir mal, puede pasar si hablamos que esto es normal... puede pasar". Cesar

Algunos estudiantes consideran que se observa mayor promiscuidad sexual en parejas homosexuales que en parejas heterosexuales.

Con respecto al comportamiento de homosexuales en una relación de pareja, los estudiantes creen que debe ser difícil manejar sentimientos como los celos, ya que podría haber alguna confusión con respecto a la cercanía de la pareja con un heterosexual. Para ellos, es importante la opinión de personas adultas que conviven con un familiar homosexual, porque consideran que es información de primera mano; pero que, probablemente, esté condicionada por prejuicios sociales.

"Yo supongo que se deben comportar de la misma forma que una pareja heterosexual, también deben tener celos por su pareja, por ejemplo: si eres homosexual y tu pareja siente celos de una mujer porque él la trata bien..., yo pienso que deben sentir celos". Alex

"Yo puedo decir eso por las personas que he visto, que he conocido; yo tenía un familiar que era homosexual que ya falleció y que ha sido de ese género, me enteré en los últimos años... hablaban de eso mis tías contaban cómo era el trato con su pareja y decían que él se iba con otra persona a las discotecas de ambiente y no le importaba, se peleaban y se metía con otro y no le importaba".Jesús

Otros estudiantes opinan que, en una relación homosexual, podría existir mayor fidelidad que en una pareja heterosexual, porque consideran que las personas del mismo sexo tienen puntos de vista comunes: los hombres se entienden mejor con los hombres que con las mujeres. Sin embargo, el sustento sobre el cual construyen esta idea de mayor fidelidad en la relación homosexual no tiene mucho valor.

"Para mí, serían más fieles que las parejas heterosexuales, sino se han dado cuenta el homosexual sigue el camino de la sinceridad, ¿qué es sinceridad? es una actitud... tienen la misma actitud, se pueden entender mejor, en cambio un bombre y una mujer tienen diferente actitud, un bombre de una cosa puede tener un punto de vista y la mujer puede tener otro, en cambio los homosexuales solo tienen un punto de vista, lo cual hace que se puedan entender mejor, es un ejemplo: cuandopapáy mamátienen un hijo: hombre y una mujer, el papá se entiende más con el hombre, es más probable que se divierta más con su bijo que con su 
bija y las madres pueden entenderse más con las hijas mujeres, por ser del mismo sexo y pueden hablar más abiertamente de sus cosas, desde su punto de vista. Los homosexuales tienen un mismo punto de vista, si comparten tendrían una relación estable porque los dos se entienden". Amelia

\section{HOMOFOBIA AFECTIVA DE LOS ESTUDIANTES}

\section{Visibilidad del homosexualismo}

Entre los jóvenes universitarios, los discursos positivos sobre la homosexualidad parecen estar relacionados con el hecho de tener conocidos o personas muy cercanas, como un compañero de estudios, donde previamente hay una declaración de su orientación sexual (la cual consideran una prueba de confianza y amistad).

"Es un muy buen amigo mío, durante todos estos 5 años de carrera... ya estoy en quinto año... simplemente... veíamos su comportamiento, nosotros pensábamos al principio que era alguien amanerado, pero él después compartió con nosotros lo que es él, ¿cómo se siente? y en realidad, él nos cuenta su experiencia y pues... normal, nos contó... éramos el grupo..., éramos el grupo de buenos amigos... qué somos entre nosotros... nos compartió y ninguno le dijo nada, al contrario, nos alegramos porque nos haya abierto su corazón edigamos no? y confesado, esto entre nosotros". Silvia

Es en el grupo de amigos y compañeros de estudios, considerados mejores amigos, en el que un joven homosexual encuentra las condiciones para expresar públicamente su orientación sexual. Probablemente con la seguridad que no encontrará rechazo, porque consideran que son sus amigos. Los estudiantes retribuyen a esta confianza con su discreción, como guardando el secreto del amigo. Esto contradice la idea que para la sociedad ver una pareja homosexual o a una persona homosexual es "normal"

“...y normal... el trato con él tampoco cambió en ningún aspecto, sigue todo normal, lo tratamos normal y nunca bubo rechazo, ni nada... bueno, porque nosotros somos amigos, quizá frente algunos compañeros, no todos se dan cuenta, no todos lo saben, pero siempre hay ese miedo de la persona a que puede haber rechazo, por eso lo compartió solo entre nosotras también con un compañero del grupo y tampoco lo divulgamos, ninada." Luis

"Bueno él... nos lo dijo tranquilo que estaba enamorado de una persona de su mismo sexo y nosotros como que al principio nos sorprendimos y le dijimos... Ab ¿era verdad no? Como que lo molestábamos, pero el tranquilo... por la confianza que nos tiene." Renato

En algunos casos, el develar su homosexualismo requiere para un joven adoptar una posición defensiva frente al rechazo social. Al menos esa es la idea que infunden a través de las personas ante quienes han admitido su homosexualidad, que ya era percibida por los demás.

\begin{abstract}
"Le preguntamos si no le importa, y él dijo: no me importa lo que los demás piensen, pero tampoco tengo que decirle a cada uno icómo soy? y iquién soy? iEso no!... bueno, es como que no le importa que los demás sepan. Él sigue su vida normal". Amelia
\end{abstract}

Algunos jóvenes recuerdan que en la escuela, durante su niñez y adolescencia, han convivido con personas homosexuales y que aparentemente podría haber una aceptación parcial de este hecho como natural. Es el grupo de amigos el que tiende a comprender y apoyar a la persona diferente que es como consideran a un homosexual. Y esta experiencia los ha llevado a tener actualmente una aceptación de amigos con orientación homosexual.

"Cuando estuve en la secundaria... en 5to año tuve un compañero, que sí manifestó que era homosexual, pero en todo el salón no lo rechazaron, lo tomaban como alguien un poco diferente, pero igual seguíamos siendo sus amigos. También, ahora... después de muchos años, un compañero que siempre ha sido mi amigo, que teníamos much a confianza, porque éramos amigos... diré: es mi amigo, manifestó que era homosexual, pero tampoco bubo un rechazo, porque como le dije en la actualidad eso ya es algo normal." Luis

"Yo en secundaria ... en el colegio siempre yo lo tomaba así, sin importancia (el homosexualismo) como juego, o sea silbaban y yo les seguía el juego, nada más y abora en la universidad en el primer ciclo, conocí a Sergio, un compañero que también es homosexual... pero todo normal con él, es mi compañero y nunca be tenido alguna discrepancia, para mi es normal. . así sea hombre o mujer, es un amigo, un compañero". Karina.

"Bueno en mi caso no, lo que pasa es que en la escuela be visto casos de lesbianismo porque estuve en un colegio de puras mujeres, entonces, no digo que sea bueno, nimalo... no lo sé, pero no es incomodidady no me sorprende. También tengo ahora, dos compañeras que son lesbianas y compañeros que son gay, bueno para mi es algo normal, pues no me parece que baya 
incomodidad ... ya lo be visto antes en mi colegio entonces, no me causa ningún rechazo o no me sorprende yo los trato con amabilidad." Silvia

\section{Rechazo hacia los homosexuales}

Algunos estudiantes enmascaran su rechazo hacia los homosexuales adoptando una postura indiferente, afirmando que "cada uno es libre de bacer con su vida, lo que quiera". En el caso de los hombres, inclusive alguien prefiere hablar en tercera persona sobre la aceptación social de un homosexual en su medio.

"Bueno a mí nunca me ha importado, como decir ino me ha importado la vida ajena!, yo no tengo nada que reprocharle y cada uno vive la vida como quiere y yo respeto a las personas así". Alex

"Pero... no es que él lo oculte, ya lleva años en la universidad y ya lo ban aceptado y como nosotros somos nuevos, no nos dábamos cuenta, pero ya lo aceptaron, ya lo conocen todos".Jesús

Un joven explica no rechazar la homosexualidad, porque considera que la vivencia de la sexualidad corresponde al espacio privado, íntimo de una persona, separado del desenvolvimiento en otros espacios sociales.

"Yo en realidad no tengo una fijación especial, pues, si es gay o es lesbiana, como le digo: he visto y tengo compañeras que son lesbianas, no me causa ningún rechazo... si tengo que conversar con ellas, por un tema de la universidad o algún tema de trabajo, lo hago sin ningún problema, no me fijo en lo que es, o no es, o en lo que bace... y tal cual es con mis companeros. Para mí son personas comunes, simplemente tienen una relación sexual diferente a la mía". Silvia

Para los jóvenes de este estudio, en realidad, no es necesario que alguien confiese su homosexualidad públicamente. Es posible identificar a un homosexual por sus comportamientos afeminados, es decir, es homosexual un hombre que asume rasgos de comportamiento del género femenino.

"En la secundaria, el hermano de un amigo mío era bomosexual... no nos dijo que era bomosexual, pero sí tenía comportamientos afeminados, caminaba como una mujer, y algunos decían que era un homosexual. Abora tenemos a un compañero que se llama Sergio y también tiene comportamientos afeminados, nunca me dijo que era homosexual, yo ya lo había notado por el comportamiento que tiene más o menos de chica". Alex
"Sí... es en los gestos, en el comportamiento, es algo como que no lo veo normal, son gestos afeminados... es lo que me parece". Edwing

"Su voz, en sus gestos, como hablan... cómo caminan y hacen gestos, como bacen las señoritas".Jesús

El catalogar a una persona como homosexual, a partir de su comportamiento afeminado, puede llevar a cometer errores. No por adoptar comportamientos, roles femeninos o masculinos, convierte a una persona en homosexual.

“... en los hombres? cuando hablan, yo creo que cuando tienes una acercamiento más directo y vas conversando más con ellos, si puedes notar en su comportamiento, como decía: iese chico a míme parecía raro!. . que sea un poco afeminado... en la forma de hablar; de expresarse, pero lo que pasa es que hay personas que sí son afeminadas pero no son gais, entonces es como que dicen mmm...". Silvia

"Yo me di cuenta que era homosexual el primer día. Era una clase de biología y por primera vez pasó él por abíy de la nada sentía que me miraba y mire atrás y me miraba así, y dije: iAb!, ¿es homosexual o no es homosexual?... bueno dije: itiene el pelo pintado de amarillo! y parecía, pregunté a alguien y me dijo que sí era homosexual". Paolo

Para identificar como homosexual a una mujer (lesbiana), se usa también el criterio de comportamientos masculinizados. Por ejemplo, usar ropa holgada y zapatillas que no resalta la figura femenina, como lo hacen las jóvenes heterosexuales en la actualidad.

En algunos casos, los jóvenes consideran que existen dos grupos de homosexuales: los que son respetados, porque intentan pasar desapercibidos ante los demás y que toman su homosexualidad como un tema privado (no muestran conductas que llaman la atención de los demás) y el grupo de homosexuales que muestran abiertamente comportamientos no varoniles a través de su vestimenta 0 usar maquillaje que, socialmente, solo es aceptable para las mujeres.

"Bueno, yo considero de que dentro de ellos bay dos grupos, el grupo de gais que simplemente se comportan de una manera alocada por decirlo así, por ejemplo. cuando caminan de manera muy llamativa, muy exagerada y el otro grupo de gais, que respetan su forma de ser o de alguna forma tratan de mantener un perfil bajo como se dice, no exagerar, ser educados, normal en ese aspecto. Si veo un gay que se comporta de esa manera sería difícil de distinguir entre sí es, o no es, pero si es 
un alocado, yo lo puedo ver con alguna pañoleta rosada... iqué sé yo! con las uñas pintadas, con los labios pintados... éfácilno?”. Silvia

"La primera vez que yo lo vi, nunca me imaginé qué era él y después ya no, ahora yo sé que él es homosexual". Luis Enrique

\section{HOMOFOBIA CONDUCTUAL DE LOS ESTUDIANTES}

La violencia por orientación sexual está presente en las aulas universitarias. Ella se expresa a través de conductas de rechazo a los homosexuales a través del maltrato psicológico y verbal. El uso del lenguaje peyorativo que subrepticiamente va orientado a demostrar el desprecio hacia los homosexuales. Así, usan como insulto la palabra homosexual, gay, cabro, etc.

"Bueno, ¿a ver?... sin maldad utilizamos la palabra cabro, chivo". Alex

"A veces le decimos Sergioooo... lo silbamos, pero no pasa de eso, tampoco se molesta lo toma bien". Luis Enrique

"Homosexuales noma, o sea a mis amigos, al homosexual le digo homosexual, ante mis amigos cabrito, gay, pero eso es entre amigos, al dirigirme a un homosexual le digo homosexual." Paolo

"Los términos fuertes (preguntado por si usa palabras despectivas para referirse a los homosexuales) los utilizo para dirigirme a mis compañeros". César

Dentro de los hogares de los jóvenes universitarios, se practica con el permiso de los adultos del hogar, la discriminación hacia los homosexuales, sobre todo, tratándose de los varones de la casa, la licencia que dan los padres (como hombres) es muy amplia. Se observa comportamientos homofóbicos de los varones de la familia. El hecho de tener una hermana, puede hacer más sensible a un joven universitario (frente a la discriminación sexual).

"Tengo la experiencia de mi hermano, se puede decir que es un poco homofóbico porque lo ve en la televisión y dice: ¿por qué están ahí?, no deberían existir... y ellos utilizan el término cabro; a las chicas les dicen: machonas, marimachas, porque hay chicas que son lesbianas y optan por vestirse como hombres ino? usan pantalón ancho, poleras, la música qué escuchan; también unos chicos que optan ... bueno, son distintos; bay chicos que son gay y se visten normal, icomo hombres!, pero hay otros gays, que ya se arreglan y que tratan ya de verse, vestirse como mujer y ellos se refieren a ellos como cabros, maricas. . bueno esos podrían ser sustérminos". Silvia

"Bueno yo be crecido junto a mi padre y junto a mis hermanos... ellos no piensan de la misma manera que yo... y he vivido toda mi vida con ellos, también tengo una bermana... bueno, soy un hombre más en la familia, he crecido más con ellos, tal vez sea por eso que tengo cierto rechazo, no sé". Richard

Los jóvenes han tenido experiencias cercanas a la homofobia durante su vida escolar. Aceptan que una de las formas de violencia escolar es la discriminación por orientación sexual, la cual se manifiesta a través de la hostilidad hacia niños y niñas que tienen actitudes contrarias a sus roles de género.

"Yo tenía un compañero que era gay, pero lamentablemente mis compañeros no lo trataban con respeto, se burlaban del él y era víctima de bullying, pero tanto le molestábamos con eso, que no le importaban ya, y al siguiente año se cambió de colegio y ya no supe más de él... y después, cuando estaba en quinto tenía un compañero que también me enteré... bueno lo molestábamos también igual, pero creo que por eso... porque lo molestábamos, mi compañero empezó a tomar otro tipo de actitudes afeminadas". Jesús

"Bueno, mis amigos también, bueno... quizás en la niñez las costumbres, bromas y comentarios que hacíamos en nuestra niñez... bueno... siempre lo hacían de estaforma". Richard

En la escuela, siendo adolescentes, uno de los canales de socialización es el grupo de amigos. En este grupo de amigos, las conductas homofóbicas se fortalecen. Así, se dan conductas evidentes de estigmatización y rechazo a la diversidad sexual.

"Bueno, en el colegio andábamos en grupo de hombres de dos o tres personas. Un hombre del salón...que andaba con las mujeres (en mi salón la mitad eran mujeres y la mitad eran varones), que paraban con nuestras compañeras. Hummmmm, nosotros los molestábamos: este maricón, eres afeminado o te gustan esas cosas, o eres una de ellas más, entonces por ese lado de cierta forma influía ino? en la forma de crecimiento ino? en la forma de optar una postura respecto eso". Richard

"Yo be estado en un colegio militar dos años, donde todos éramos hombres y siempre molestan a uno, que no podía hacer planchas, lo molestaban como bomosexual y siempre se reían por eso, ya que en el ejército 
hablan malas palabras, los capitanes, comandantes, técnicos, todos tratan como si fueran hombres y si hay un homosexual, sus compañeros de cuadra siempre lo marginaban y siempre va a ser marginado, porque se rigen por ese principio de quéson hombres". Paolo

Siendo que en la escuela no se practican políticas de exclusividad sexual, los jóvenes consideran que en la universidad están aprendiendo a convivir en la diversidad, sin que eso, necesariamente, signifique aceptar las otras orientaciones sexuales diferentes a lo heterosexual.

"Se puede decir que no hay comparación de lo que vivía en el colegio a lo que vivo ahora en la universidad es otra cosa, porque abora no tengo el mismo comportamiento que en el colegio. Abora convivo más, respeto más, a los a compañeros y compañeras a todosporigual". Renato

Algunos jóvenes tienen la tendencia a justificar la violencia y discriminación contra los homosexuales del grupo (en la universidad) culpándolos por expresar libremente su orientación sexual. Al parecer, los transexuales causan un mayor rechazo de parte de ellos.

"Por ser afeminados, los de mi salón se agarraban de eso y no solo mi salón, sino todas las secciones y abora ya no sé nada, no sé de sus vidas, pero igual en la universidad tenemos un compañero que era gay, no nos dijo obviamente, pero en sus actitudes, en sus acciones $y$ también cuando hay ceremonias cambiaba yutilizaba ropa de chica, mi compañero se cambiaba de ropa, nuestro compañero abora igual se cambia de ropa y cuando iba a fiestas a veces era irreconocible". Jesús

\section{NORMALIZACIÓN DE LA VIOLENCIA HOMÓFOBA DE LOS ESTUDIANTES}

Si bien es cierto que la Constitución Política del Perú y la Declaración Universal de los Derechos Humanos, señalan que todos somos iguales ante la ley, en derechos y deberes, en la actualidad, esto no se cumple ya que existen derechos negados a las minorías sexuales. Dos puntos importantes al respecto: unión civil y paternidad homosexual. Los jóvenes universitarios están dispuestos a aceptar la homosexualidad; pero no que todos los seres humanos tengan los mismos derechos.

"Cuando estamos en grupo o estamos solos normal.. igual frente a mi amigos, ha sido siempre el mismo trato". Jesús

"Bueno la verdad, no estoy en contra, tampoco me afecta, son personas iguales a nosotros y también tienen derechos, así que no creo que afecte a nadie, simplemente a veces por temas religiosos... pero no tiene nada que ver". Luis Enrique

Algunos jóvenes disfrazan su rechazo hacia la igualdad de derechos de los homosexuales ante la ley, a través de la indiferencia que no es otra cosa que un rechazo no frontal. Ellos dicen que mientras se respeten sus derechos, no les afectará que los homosexuales ejerzan sus derechos sexuales.

"La verdad que si tienen las condiciones adecuadas para mantener y adoptar un hijo, yo estoy de acuerdo, pues a mí, no me afecta ien qué me puede afectar?... no sé... ellos saben lo que hacen. A veces creo, que ellos tienen más perspectiva de la vida, porque han sido maltratados y a veces discriminados, para mínormal, no me afecta en nada, si se acepta o no que puedan adoptarniños". Alex

"Yo actualmente diría que no estoy en contra de los homosexuales, o sea ... estoy en contra de la discriminación, no sé cómo explicarme, hay un dicho que dice: ino importa la sangre que corra, hasta que corra nuestra sangre!, muchos dicen: ia mí no me afecta!, así que ieso no me importa!, muchos dicen eabhbhbhbhbhbh, bueno, i a mi no me importa! iEs su vida!, ia mí me no afecta!, en verdad eso es mentira, eso debe de importarnos a todos... o sea ... antes era cristiano y cuando se propuso esa ley (unión civil) en la iglesia se generaron actas para firmary que esa ley no se aprobara... ". Paolo

Los jóvenes pueden aceptar (como posibilidad) la unión civil, pero no aceptan de ninguna manera darles la oportunidad de ser padres a través de la adopción, porque consideran que los niños estarían expuestos a abusos sexuales, daños psicológicos o estos terminarían siendo también homosexuales.

"Creo que ese aspecto es muy delicado, yo en lo personal be escuchado muchas noticias de parejas gais que han adoptado, y esos niños han sido víctimas de violación, entonces yo al principio no tenía ningún problema porque son personas normales pero, al saber esto como que... puede ser y puede pasarle algo a los niños y no tiene por qué pasar, ... además, los niños también pueden tenercierta inclinaciónpor ser gay o ser lesbianas por criarse en ese entorno desde chiquitos ... creo que no estaría muy de acuerdo con la adopción". Silvia

"Yo opino que eso de la unión civil... pues seria para mí... no sé, sería igual.. bueno si quieren casarse, supongo que se casarian, pero, adoptar bijos no?". Alex

"Yo en el caso de las bodas, si estaría de acuerdo, pero obviamente con reglas, porque psicologicamente tienen 
que estar bien, igual para tener hijos... cualquier pareja puede adoptar pero con buenas condiciones para ellos, para no fomentar que también su bijo se incline a ser bomosexual".Jesús

Una de las preocupaciones que tienen los jóvenes sobre si es conveniente que las parejas de homosexuales se conviertan en padres: es el rechazo de la sociedad. Piensan que la violencia homofóbica pueda afectar al niño en su normal desarrollo.

"Tienen que ser responsables de lo que están haciendo y también actuar como personas normales, no por el hecho de ser es homosexual van a actuar de una manera extraña, porque existe el caso de que hay parejas que son homosexuales y hay gente que les silban por molestar y esas personas gritan, se emocionan y hacen gestos, cosa que no debería ser así, bueno creo que no debería ser así... los respeto, pero deberían actuar de buena manera".Jesús

Los jóvenes pueden reconocerles el derecho al trabajo y el derecho a la participación política; pero tienen dificultades para aceptar los derechos sexuales de los homosexuales. Hay un intento de separar la vida sexual, de la vida social y política de los homosexuales.

"Si se legaliza el matrimonio homosexual o si dos personas del mismo sexo se quieren no tengo ningún problema, en el caso de que tengan oportunidad de un trabajo y se les niegue por tener una orientación sexual distinta, creo que sería injusto porque hay personas que tienen una orientación sexual distinta, pero son inteligentes eso no los limita en cuanto a su desenvolvimiento laboral, académico o en otros aspectos, porque son personas que pueden aportar muchisimo en el desarrollo de la sociedad y en el trabajo, en ese aspecto no creo que deberían limitarse por tener una orientación sexual distinta.. Bueno es mi forma de pensar". Silvia

"La homosexualidad está relacionada solo con la sexualidad. Como vives tu vida, como tú te desenvuelves socialmente y politicamente, esa es tu decisión y no tiene nada que ver con lo anterior, también puedes pertenecer a un grupo político o ser un presidente. En el ejército tampoco debe haber discriminación hacia el bomosexual, pero lastimosamente esto se da. Eso se mantiene... ". Luis Enrique

Algunos jóvenes rechazan la homosexualidad y la transexualidad, basando su opinión en la religión que profesan. Es probable que el concepto de homosexualidad que tienen estos jóvenes esté basado en el sexo y la genitalidad solamente, y no en la identidad sexual. Basándose que en la religión cristiana la homosexualidad es una aberración castigada por Dios.

"Sé que no es mi vida, pero no es que no quiero que ellos sean felices, sino que ellos me importan tanto que no me gusta que hagan eso... es decir... prácticamente no es que no los quiera dejar vivir su vida y me decía: tú no tienes nada que ver con ellos, pero yo decía: Sí, me preocupan, también era algo biblico iusted conoce eso de Sodoma y Gomorra?, eee... Sodoma eran hombresy tenían relación con hombres y en Gomorra vivían mujeres y tenían relaciones con mujeres y Dios veía tanta lujuria que castigó a esas dos ciudades, hay un versículo que dice que los hombres que se acuesten con otros hombres, serán castigados e irán al infierno, es decir, no solo habla de los homosexuales, sino también habla que estas personas cometen pecado". Paolo

Para los jóvenes, una persona homosexual tiene más acceso al ejercicio de derechos (como ejercer cargos públicos) si oculta su orientación sexual a la sociedad. Es decir, que declarar su homosexualidad le puede traer el desprestigio social y la desacreditación para ejercer un cargo público de importancia.

\begin{abstract}
"Yo creo que no es un impedimento, ya que no sabemos cuántas personas son homosexuales y no lo demuestran, o sea... pueden haber personas homosexuales en cargos públicos, pero sin embargo no nos damos cuen$t a$, una persona homosexual se pude comportar como es, sin exagerar, ni ser afeminado. Me ban contado que bay personas así, que se comportan normalmente... así... pero tienen esa inclinación, yo creo que normal pueden tener un cargo público o cualquier cosa". Luis
\end{abstract}

"No, ningún impedimento, si son bomosexuales no podemos discriminar a alguien por su homosexualidad".Jesús.

Algunos jóvenes consideran que la visibilidad normalizada de los homosexuales ha sido posible gracias a las declaraciones públicas de su homosexualidad que han realizado personajes públicos, a través de los medios de comunicación social, lo cual en cierta forma es valorado positivamente por ellos.

"No es que hayan aumentado los homosexuales, sino que antes no era algo muy común, la gente no los aceptaba... como se dice: no salían del closet, no bacían pública su homosexualidad, pero abora como ya se está aceptando, la gente se siente más libre y la gente es más respetada, más segura y ya lo dicen y hacen que todos sepan que son homosexuales". Paolo 
"Yo pienso que los personajes públicos tuvieron el valor para bacer pública su orientación sexual, tomaron valor para decirlo y ya no se esconden, yo pienso que por eso, van a aparecer más homosexuales". Alex

\section{TEMOR A SUFRIR CONTAGIO: EL ESTIGMA DEL} HOMOSEXUAL

Al parecer, el rechazo al gay es mayor que el rechazo a la lesbiana. Esto tiene que ver con un temor al contagio de la homosexualidad o el simple temor a ser estigmatizado también como ellos. Estos temores están presentes en los hombres.

"En mi caso, creo que rechazaría más a los gay que a las lesbianas, por el hecho que son del mismo sexo que yo... hay una cierta incomodidad y prefiero evitarlos... de cierta forma tengo contacto directo con ellos, son amigos y compañeros de trabajo". Richard

"Tanto en grupo como individualmente es un compañero más... tendrá sus gestos y todo eso, pero es un compañero más, no es que lo aislemos, ni que lo discriminemos". Luis Enrique

El grupo de amigos juega un papel importante en el temor al contagio del estigma del homosexual. Personalmente algunos jóvenes están dispuestos a mantener contacto social con pares homosexuales; sin embargo, el temor al qué dirán sus amigos al saberlo, hace que mantengan su distancia y rechacen sutil o frontalmente la amistad de un homosexual.

"Yo la primera vez que bablé con él, fue a través de Facebook y él siempre hablaba como que: iboli!, yo siempre hablaba como hombre para que no sintiera nada, le decía ibola primo! ¿Quépasa men? Asíle decía nada másy una vez en una velada abrieron mi celular $y$ vieron todito $y$ estaban que me molestaban, pero abora cuando estamos en grupo o cuando estoy solo igual lo molesto, lo silbo y solo por jugar, pero nada por maldad, ni nada de eso yél se ríe y toda la cosa”. Paolo

Probablemente haya más disposición a aceptar la cercanía de una persona homosexual en las mujeres que en los hombres. Entre los hombres hay actitudes de rechazo hacia la homosexualidad, según dicen no es odio al homosexual; pero lo cierto es que existe un rechazo manifiesto, pues evitan la cercanía de un homosexual por distintas razones, que pueden ser el desprestigio sexual o el temor a un contagio de la homosexualidad.

"En realidad, todo normal, porque también no me han hablado directamente; pero sé casos de otros compañe- ros de la escuela que también son de esa orientación sexual, son homosexuales y normal, ellos también se comportan normal: en sus estudios, en sus clase y yo también normal, porque son mis amigos y mis compañeros, no tengo ningún sentido de rechazo, ni los miro mal, por el contrario, como siempre fuimos amigos, no hay diferencia”. Silvia

Algunos jóvenes no saben o no pueden expresar su rechazo hacia los homosexuales. Los hombres tienen la necesidad de proyectar una imagen viril para las mujeres y verse relacionado con un hombre homosexual afecta esta imagen que quieren proyectar hacia ellas. Concretamente le temen al contacto físico con un hombre homosexual, ello podría ser probablemente por el temor al contagio del estigma.

"No es que los odie, solo que prefiero evitarlos... En mi caso se puede decir, que me genera... no sé cómo decirlo... o sea tener una conversación con una persona gay, mepone nervioso, no sésime siento incómodo pero... No es que los deteste o de alguna forma trate de discriminarlos, por decirlo así, solo que prefiero mantener cierta distancia". Richard

Para los jóvenes, el homosexual varón se siente más identificado con las mujeres. Ellas lo acogen en su grupo y comparten con él conversaciones relacionadas con el género femenino. Eso les parece natural, en el grupo de amigos hombres un homosexual no encajaría bien.

\begin{abstract}
"Yo creo que las mujeres lo tratan normal, y no se dan cuenta que tienen demasiada confianza con ellas... Yo me acerco a ellas cuando están conversando, sin querer escucho y hablan cosas de chicas... Prácticamente es una mujer más". Alex
\end{abstract}

Algunos jóvenes superan el temor al contagio del estigma homosexual gracias a que tienen un alto concepto de la amistad. Es en nombre de un sentimiento fortalecido en el tiempo que pueden llegar a superar el temor al contagio del estigma.

“... ahora después de muchos años un compañero, que siempre ha sido mi amigo, que teníamos mucha confianza, porque éramos amigos, manifestó que era bomosexual, pero tampoco bubo rechazo por que como le dije en la actualidad eso ya es algo normal". Luis 


\section{ANÁLISIS Y DISCUSIÓN DE RESULTADOS}

Una de las consecuencias importantes de la homofobia en las instituciones educativas es el abandono de los estudios por niños y adolescentes que sufren angustia y culpa como producto de ser discriminados en sus escuelas. Como producto de los estereotipos aprendidos, los niños, niñas, y adolescentes estigmatizan a sus pares que expresan roles no asignados a su género. Al respecto Riesenfeld (2012) manifiesta que los niños descubren su cuerpo, lo exploran, sienten placer y también se enamoran; el autor dice que en la infancia la orientación sexual no está relacionada con la genitalidad, sino con el enamoramiento y la atracción. Por lo que es irracional afirmar que un niño es o será gay en su vida adulta.

En este estudio, se encontró una homofobia cognitiva, conductual y afectiva en los jóvenes universitarios varones. Las mujeres se muestran más tolerantes al aceptar la diversidad sexual. En algunos casos los jóvenes señalan que ellos no son homofóbicos pero han participado de la violencia de género afectiva y conductual en su niñez, adolescencia o en la actualidad. Generelo y Pichardo (2005) afirman que el sistema de transmisión de estereotipos acerca de la sexualidad y el reparto de roles de géneros, no daña exclusivamente a los homosexuales, sino a todo el mundo. Impide una correcta convivencia entre compañeros, divide a chicos y chicas, pone barreras y levanta muros interiores, especialmente entre los varones, que se ven constreñidos todavía, a un desarrollo emocional en el que la premisa fundamental es el rechazo de lo que se entiende como femenino: emociones, afectos, solidaridad, etc. En resumen, existe una visión negativa y errónea de la homosexualidad, entre los jóvenes universitarios. Basados en estereotipos rechazan y evitan relacionarse con homosexuales. Los varones sienten temor al contacto físico, les desagrada las muestras de afecto a la libertad con la que algunos homosexuales se hacen visibles. La homofobia cognitiva y afectiva se concretizan en una homofobia conductual, la cual se expresa desde el grado más leve que es hacer bromas sobre homosexuales hasta la violencia expresa del insulto y animadversión.

Los jóvenes que tienen discursos positivos hacia la homosexualidad reconocen como un acto de valentía la declaración abierta de la homosexualidad de una persona cercana a ellas. Sin embargo, esta valoración no es suficiente para apoyarlo realmente frente a la homofobia afectiva de los otros, que ocurre en su presencia y en cierta forma se le culpa por ello por ser diferentes: ser afeminados, tener una voz diferente, vestirse poco femenina o poco masculina.

Generelo y Moreno (2007) afirman que la homosexualidad puede entenderse si se habla de ella y es algo muy complejo como para temer que se pueda adquirir por contagio. Traemos a colación esta idea debido a que entre los jóvenes universitarios la homofobia cognitiva y afectiva tiene como una de sus causas el temor al contagio de la homosexualidad que la sociedad infunde en los heterosexuales desde la niñez. Asimismo, mencionan que se debe enfrentar una educación en el respeto a la diversidad afectivo-sexual. Por varias razones: porque es una realidad y en la escuela existe una diversidad que no está siendo explicada a los estudiantes, lo que afecta la convivencia armoniosa en la diferencia; porque un porcentaje entre 5 y $10 \%$ de estudiantes pueden estar pasando por una crisis de identidad sexual; porque hay que reducir las crisis familiares ante el descubrimiento de la homosexualidad de un hijo; los varones afirman su masculinidad por oposición a lo femenino y eso los limita emocionalmente; y el respeto a la diversidad permite la convivencia.

La homofobia cognitiva y afectiva ha sido interiorizada a través de la asimilación de mensajes negativos recibidos a temprana edad en la familia, colegio, medios de comunicación, etc. Los jóvenes no se encuentran sensibilizados respecto a cómo pueden afectar con su rechazo a las personas por su condición de homosexual: bajar su autoestima, reprimirse en sus expresiones afectivas, sentir culpabilidad. Dicen que respetan y que es normal ver parejas de homosexuales, pero siguen sintiendo que ellos tienen comportamientos antinaturales y amorales, como una enfermedad. Esto tiene una explicación, en el contexto occidental vemos que el término homosexualidad nace en contraposición a la heterosexualidad, que considera la sexualidad "normal”, como los señalan Arana y Portocarrero (2014). Esta idea se complementa con lo afirmado por quienes señalan que las normas de género operan exigiendo la encarnación de ciertos ideales de feminidad y masculinidad, que van casi siempre ligados a la idealización y naturalización de la unión heterosexual, impuesta como modelo único. De ello, se deduce que la homosexualidad no es normal.

\section{CONCLUSIONES}

Los universitarios muestran homofobia cognitiva, afectiva y conductual, la cual es practicada en los hogares y las instituciones educativas, promovida por los sectores conservadores de la sociedad y por los medios 
de comunicación. A pesar de expresar que no rechazan a los homosexuales, sí los estigmatizan aceptando la homofobia conductual de sus pares, les parece aceptable darles derechos políticos y sociales como la participación política y el derecho al trabajo, pero no apoyan la defensa de sus derechos sexuales: hay rechazo hacia la paternidad tanto en hombres como en mujeres, aunque estarían de acuerdo con la unión civil.

Es necesario capacitar a docentes y padres para evitar la homofobia en los hogares y en la escuela. Las instituciones educativas no deben tolerar y perpetuar la hegemonía heterosexista y el discurso homofóbico ya que son prácticas que violan los derechos constitucionales y humanos de los ciudadanos.

\section{REFERENCIAS BIBLIOGRÁFICAS}

Arana, L. y Portocarrero, A. (2014). Diversidad sexualy educación superior. MISAEL, Nicaragua.

Recuperado de: https://unainclusivacr.files. wordpress.com/2014/07/08-unidad-5diversidad-sexual.pdf

Borrillo, D. (2001) Homofobia. Barcelona: Bellaterra.

Campo, K., Rodríguez, G. y Trías, L. (2008). Actitudes de estudiantes universitarios hacia la bomosexualidad. Psicología. Vol. XXVII (2): 89-118.

Cárdenas, M. y Barrientos, J. (2008). Actitudes explícitas e implícitas hacia los hombres homosexuales en una muestra de estudiantes universitarios en Chile. Psykhe 17 (2): 17-25.

Castañeda, M. (2000). La experiencia homosexual: Para comprender la homosexualidad desde dentroy desde fuera. México, DF, Paidós.

CONAPRED. (2010). Encuesta nacional sobre discriminación en México (ENADIS). Resultados generales. Recuperado de:

http://www.conapred.org.mx/userfiles/files/En adis-2010-RG-Accss-02.pdf

Friedman, Richard y Downey, Jennifer. (1994). Homosexuality. New England Journal of Medicine, 31:923-930

Fundación Reflejos de Venezuela. (2015). Manual educativo para la diversidad. Recuperado de: http:www.fundacionreflejosdevenezuela.com

Generelo L. y Pichardo, G. (2005). Homofobia en el sistema educativo. Comisión de Educación de COGAM. Universidad Autónoma de Madrid. Recuperado de:

http://www.cogam.es/_cogam/archivos/1437_ es Homofobia\%20en\%20 el\% 20Sistema\%20Educativo\% 202005.pdf.

Generelo, L. y Moreno, C. (2007). Diferentes formas de amar Guía para educar en la diversidad afectivo-sexual. Comisión de Educación de COGAM. Madrid. Recuperado de:

https://espanol.free-ebooks.net/ebook/ Diferentes-Formas-de-Amar-Guia-paraEducar-en-la-Diversidad-AfectivoSexual/pdf?dl\&preview

Goffman, E. (1993). Estigma. La identidad deteriorada. Buenos Aires: Amorrortu.

Lizana, V. (2009). Representaciones sociales sobre beterosexualidad y homosexualidad de los/las estudiantes de pedagogía en los contextos de formación inicial. Estudios Pedagógicos. Vol. XXV (1): 117-138.

Pichardo, J., Molinuevo, B., Rodriguez, P., Martín, N. y Romero, M. (2007). Actitudes ante la diversidad sexual de la población adolescente de COSLADA (Madrid) y San Bartolomé de Tirajana (Gran Canaria). Ayuntamientos de Cosladay San Bartolomé de Tirajana, FELGTB.

Pulido, M., Huerta, A., Muñoz, F. Pahua, E., PérezPalacios, P. y Saracho, S. (2013). Homofobia en universidades de la Ciudad de México. Revista Intercontinental de Psicología y Educación, 15 (2): 93-114.

Riesenfeld, R. (2012). Papá, mamá, soy gay. Grijalbo. Recuperado de:

http://www.fiuxy.net/ebooks-gratis/3587347papa-mama-soy-gay-rinna-riesenfeldepub.html

Snively, C., Kreuger, L., Stretch, J., Wilson, J. y Chadha, J. (2004). Understanding homophobia. Journal of Gay \& Lesbian Social Services, 17, 59-81.

Toro, J. y Varas Díaz, N. (2004). Los otros: prejuicio y distancia social hacia hombres gay y lesbianas en una muestra de estudiantes de nivel universitario. International Journal of Clinical and Health Psychology, 4 (3): 537-551. 